\title{
Regression to Egocentrically Determined Description of Form Under Conditions of Inattention
}

\author{
Irvin Rock and Romi Nijhawan \\ University of California, Berkeley
}

\begin{abstract}
Although, ordinarily, upright objects are readily recognized by observers who are tilted, it is hypothesized that this is achieved by a process of correction. The first stage of that process is held to be a description of the object in relation to the biologically more primitive system of retinal coordinates. In order to test this hypothesis, tilted subjects were required to view figures under conditions of inattention (Experiment 1) or divided attention (Experiment 2). Under such conditions description may not proceed beyond that first stage. The results showed that recognition was higher for figures that maintained their orientation with respect to the retina (although they were then tilted in the environment) than for figures that remained upright in the environment (although they were then disoriented with respect to the retina). This outcome is the very opposite of what occurs under conditions of attention.
\end{abstract}

When a tilted observer views an upright object or figure, there is little if any difficulty in perceiving and recognizing it. Only if the observer's head is inverted or, for lesser head tilts, only if the material to be recognized is in some sense complex, such as cursive writing, is there any evidence that the disoriented retinal image leads to difficulty in recognition. Instead, what seems to matter for correct processing and recognition is that the directions top, bottom, left, and right are appropriately assigned to the object. Ordinarily such assignment of directions is based on gravity information and the coordinate vertical and horizontal axes of the visual scene. Therefore, despite the changing orientation of the retinal image when the observer is tilted, there is no change in the assignment of directions to objects and thus no failure of recognition (Rock, 1973).

Nonetheless, there are reasons for believing that the achievement of appropriate perception and recognition under such circumstances is the end result of a process of correction in which the orientation of the retinal image plays a role. The perceived orientation of objects in relation to the body of the observer is based on the orientation of the retinal image (Rock, 1954). If an observer views an object or figure that is in a horizontal plane, the perceived top of it can only be given egocentrically, and this perception in turn is directly given by the orientation of the object's retinal image. We suggest that such perceived egocentric orientation is the direct result of a biologically primitive assignment of orientation to objects in relation to the self on the basis of the retinal coordinates. Thus, the image of a vertical line is experienced as aligned

This research was conducted when both authors were at Rutgers University, New Brunswick, New Jersey.

The research was supported by Grant MH-30865 to Rutgers University, and the preparation of the manuscript was supported by Research Scientist Award MH-00707 to the University of California, Berkeley, both from the National Institute of Mental Health, Irvin Rock, principal investigator.

Correspondence concerning this article should be addressed to Irvin Rock, Department of Psychology, University of California at Berkeley, Berkeley, California 94720. with the long axis of one's head, a horizontal line with the head axis that is parallel to the two eyes, the downward direction on the retina with an upward direction in relation to the self, and so forth.

Notwithstanding this fact, one might maintain that egocentric orientation does not play a role in the perception of object orientation when, as is almost always the case, information is available as to how things are oriented in the environment. One might think that ordinarily there is no such role of egocentric orientation based on retinal orientation. However, some clues suggest that there is. We already hinted at two reasons for believing so. One is that it does become difficult to recognize certain kinds of material when retinal orientation is no longer upright. Recognition of handwriting is impaired if an upright page is viewed with the head tilted $90^{\circ}$. Recognition of such writing and of facial expression and identity is severely impaired when the observer views these objects from an inverted position of the head. In these cases recognition is not impaired if the objects are tilted or inverted in the environment so that they are upright on the retina (Köhler 1940; Rock, 1973; Thouless, 1947). Moreover, there is a decline in the recognition even of simpler forms when they are viewed with the head inverted (Rock, 1956). Finally, it is interesting to note that although one easily recognizes simple upright figures, such as letters or numbers, from a tilted position of the head, or when they are tilted, say, $90^{\circ}$ and the observer is upright, there is a sense in which these figures appear to be phenomenologically different from when they and the observer are both upright. The letters and numbers in Figure 1, although easily recognizable, do not look entirely normal. We suggest that this effect is the result of a description based on the object's egocentric orientation that goes along with a description based on its correct orientation.

Therefore, we hypothesize that perception of form always begins with a description based on the subtle interplay of the geometry of the object's image and the assignment of directions to it on the basis of egocentric coordinates. However, typically when we view upright objects from a tilted position, to achieve appropriate perception we must suppress that egocentric description because we have good information 


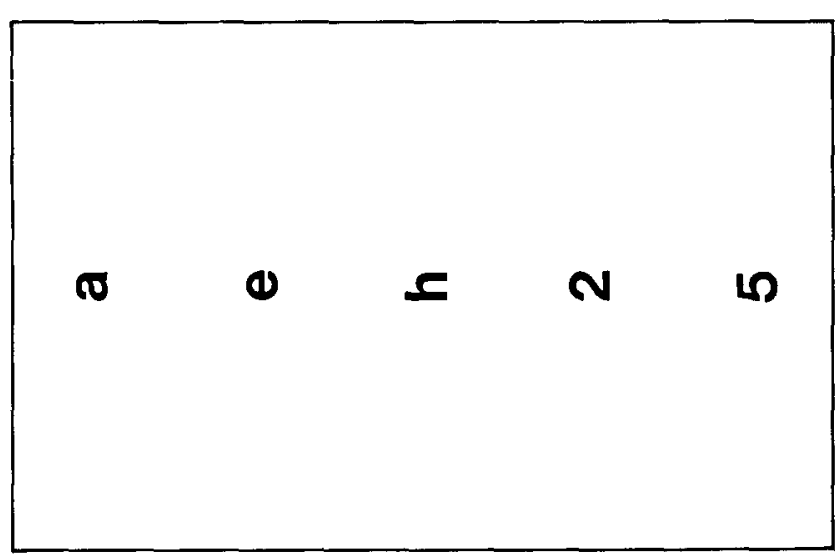

Figure 1. Tilted letters and numbers, although easily recognized, do not look the same as when they are upright.

concerning objects' orientations in the world. The egocentric description is then superseded by one in which the directions of the object are assigned on the basis of such information. The final phenomenal shape is then based on the subtle interplay of the object's geometry and its direction assigned on the basis of information of the object's orientation in the world.

The experiments described herein were designed to reveal the reality of the first stage of description based on egocentric coordinates. We reasoned that the final description based on environmental coordinates most probably requires attention. It is based on a process of interpreting the retinal image in terms of information such as that from gravity receptors and thus can be thought of as a constancylike mental operation. The role of attention in achieving shape and size constancy has recently been demonstrated by Epstein and Lovitts (1985) and Epstein and Broota (1986). We thus reasoned that if attention is withdrawn when one is viewing an upright object from a tilted position of the head or entire body, the perception may remain at the more primitive level of description based on the egocentric coordinates.

Although we investigated the effect of inattention (or divided attention), our research was not primarily concerned with the issue of attention and inattention. Rather, our manipulation of the degree of attention was an experimental tool with which to investigate the process of correction in form perception. However, it is true that the effect of inattention or divided attention on perception is itself of major theoretical interest, so the findings will undoubtedly have importance for more general issues of perception.

\section{Experiment 1}

There were four conditions in Experiment 1, which were combinations of two levels of attention and two head orientations. Attention could be either allocated to or withdrawn from the figures, and the subject's head was either upright or tilted $90^{\circ}$ while the figures were being viewed in a learning phase. Thus the four conditions were attention withdrawn, head tilted; attention withdrawn, head upright; attention allocated, head tilted; and attention allocated, head upright. In all four conditions subjects fixated on a point where subsequently a figure was presented. The instructions were to either look at the figures or perform a distractor task.

\section{Method}

\section{Subjects}

Seventy-two unpaid undergraduates at Rutgers University participated in this experiment as partial fulfillment of a course requirement. Twenty subjects were assigned to Conditions 1 and 2 (attention withdrawn), and 16 subjects to Conditions 3 and 4 (attention allocated).

\section{Apparatus}

A Scientific Prototype three-channel tachistoscope (model GB) was used to present the stimulus cards. All three tachistoscopic fields were square in shape and thus did not contribute to any frame-of-reference bias. That is to say, either the objective top or the objective side of the square frame could serve as the phenomenal top. Since figures were tilted only $90^{\circ}$ the side of the square could serve as "top" that would then be aligned with the subjects' egocentric "up," or the top of the square could serve as "top" that would be aligned with the environmental "up" direction. Therefore the square frame would not bias the result one way or the other. Attached to the front of the tachistoscope was a chin rest that allowed the subject's head to remain stationary when the stimuli were viewed with head upright. In the head-tilted condition, the subject rested his or her head on a horizontal wooden surface with padding that was also attached to the tachistoscope.

\section{Figures}

Each stimulus figure was drawn on a $7 \times 9.5$-in. piece of white cardboard with a $1-\mathrm{mm}$ black ink pen. The figures subtended a visual angle of approximately $2.25^{\circ}$. There were two sets of cards, one for the learning phase and one for the test phase. Each learning-set card consisted of one central stimulus figure and two clusters of equally spaced dots at the upper left and lower right (see Figure 2). Each cluster projected a visual angle of approximately $1^{\circ}$. There were 12 such cards in the learning set.

The figures were abstract line drawings lacking any obvious meaning. They were drawn according to the following criteria. First, they were such that they were expected to undergo a change in phenomenal appearance when seen tilted $90^{\circ}$. Toward this end, the figures were not to contain distinctive local features that could be recognized. Moreover, the effect of change of orientation on phenomenal shape was such that the subjects were not likely to detect that a figure has been rotated. This requirement obviously ruled out the use of familiar figures. All figures were stylistically similar to one another in that they were irregular, closed shapes of approximately the same level of complexity. On each card, two clusters of black dots $(4 \mathrm{~mm}$ in diameter) were present along an axis $45^{\circ}$ off the vertical in the counterclockwise direction. This diagonal axis was selected so that the dots would not provide a frame of reference favoring the gravitational coordinates over the retinal coordinates or vice versa for an observer tilted clockwise $90^{\circ}$. The separation between the two clusters (center to center) was approximately $4.5^{\circ}$. The stimulus figure was placed between the dot clusters. Both clusters consisted of 5 to 7 dots. Thus the cards consisted of the central novel figure and either the same or a different number of dots in the two clusters. 


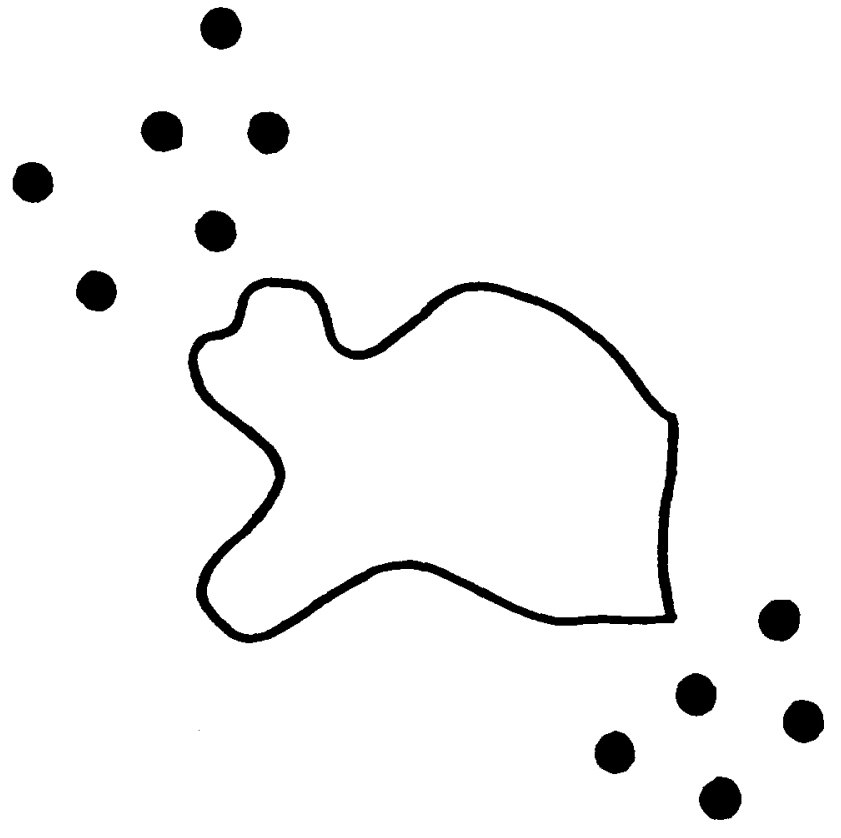

Figure 2. One of the figures used in Experiment 1 with the numerosity task consisting of dots on the upper left and lower right.

The test cards, 18 in number, did not contain any dots. To the 12 learning-set figures were added 6 new figures in order to be able to assess the level of recognition performance. Six of the learning-set figures maintained their orientation between the training and the test, and the other 6 were rotated $90^{\circ}$ counterclockwise for the test. The new figures were stylistically similar to the learning-set figures.

\section{Procedure}

Seventy-two subjects were divided into four groups corresponding to the four conditions. A between-subjects design was used. Each condition consisted of two phases, learning and test.

Learning phase. The same set of 12 cards (with figures and dots) were used during the learning phase in all conditions. All the presentations were viewed monocularly, because both eyes could not be accommodated by the size of the tachistoscopic field that was visible given the location of the subject's head. The subject sat on a chair and positioned him- or herself on the chin rest. Before the first practice trial the subject was instructed to view a fixation point ( 2 $\mathrm{mm}$ in diameter) that was located where the figure would appear subsequently. In the attention-withdrawn conditions, the subject was told to attend to the dots that would appear and make a decision regarding their numerosity. It was explained that the response could be either "same" (same number of dots in each group) or "different" (different number of dots in each group). The presence of the figure in the central region was justified by telling the subject that one purpose of the experiment was to study the effect that these figures might have on their performance.

In the attention-allocated conditions, the subject was told to ignore the dots, their presence being attributed to requirements of a previous experiment. Subjects were instructed simply to look at the figures, and no mention of a later test was made. A practice card was then shown tachistoscopically. The subject was told that the best strategy would be to hold the eyes still because some time would be wasted by moving them.
All the instructions and preliminary practice were given with the subject sitting upright. After this, subjects in the head-tilted conditions were asked to sit on a different seat with their head tilted $90^{\circ}$ clockwise, resting on a padded surface. (It was assumed that information concerning the orientation of the figures in the environment was provided by gravity and whatever visible contours in the scene or the display served as a visual frame of reference. No attempt to separate or to investigate these factors was made in the present experiments.) Subjects in the head-upright conditions remained seated upright.

In the attention-withdrawn conditions, each card was presented three times for $500 \mathrm{~ms}$ because in the pilot testing fewer than three presentations resulted in chance level of recognition. Thus, there were a total of 36 presentations ( 12 cards, three repetitions), with the order randomized within each set of 12 cards. In the attention-allocated conditions, each card was presented once for $500 \mathrm{~ms}$. In pilot testing it was clear that one such exposure sufficed for learning, that is, for above-change recognition. Thus there were a total of 12 presentations. For all conditions the presentations were separated by a time interval of $3 \mathrm{~s}$. Following every stimulus presentation, a blank field of the same brightness as the stimulus field came on for $200 \mathrm{~ms}$. Each trial began with the subject fixating the dot presented in a separate channel of the tachistoscope.

Test phase. After the learning phase, each subject was tested for recognition. All subjects sat upright with head stabilized by the chin rest. The 12 figures used in learning were divided into two groups, A and B. For half the subjects, Group A figures were upright and Group $B$ figures were tilted $90^{\circ}$ counterclockwise; for the other half Group B figures were upright and Group A figures were tilted $90^{\circ}$ counterclockwise. Because the subjects in the head-tilted conditions were tilted clockwise in the learning phase, figures that were tilted counterclockwise in the test fell in the same orientation on the retina; figures that remained upright in the test fell in a different orientation on the retina, namely, one that was rotated by $90^{\circ}$. All presentations during the test phase for all conditions were also viewed monocularly. As a sample, the subject was shown the figure that was accompanied by dots in the practice trial preceding the learning phase. The subject's task was to say either "yes" (the figure is from the learning set) or "no" (the figure is not from the learning set). The subjects were asked to guess when they were uncertain.

Interview. At the end of the test phase subjects were interviewed. The subjects from the attention-withdrawn conditions were asked, "Do you feel that some of the cards of the training set were shown more than once?" An answer in the affirmative led to a further question: "Do you say this because of the familiarity of the groups of dots or of the figures?" The subjects from both conditions were asked, "Did you feel that some of the test figures were rotated versions of the training figures?" If a subject said yes to this last question, the further question was, "Did you say yes to such figures or no?"

\section{Results}

Because each condition was run with separate subjects, we shall consider the results of each one separately.

\section{Condition 1: Attention Withdrawn, Head Tilted}

Since subjects in Condition 1 were tilted clockwise in learning and were upright in the test, the test figures that were now rotated counterclockwise maintained their orientation with respect to the retina. The upright figures, on the other hand, kept their orientation constant with respect to gravitational coordinates but changed their orientation with respect to the retina. If lack of attention did render a description 
consistent with retinal orientation, we could expect a predominance of "yes" responses to the retinally unchanged figures that in the test were actually tilted $90^{\circ}$. The mean number and percentage of "yes" responses for 20 subjects for new (N), retinally unchanged $(R)$, and environmentally unchanged $(E)$ figures are presented in Table 1. A three-group, one-way, repeated measures analysis of variance (ANOVA) was performed on the data. A significant $F$ ratio was obtained, $F(2$, $38)=27.32, p<.01$. An honestly significant difference (HSD) test was used to test the significance of differences between pairs of test-figure types, and the analysis is presented in Table 2. The $R$ and $E$ test-figure types differed significantly from the $\mathrm{N}$ test-figure type $(p<.01)$, and the $\mathrm{R}$ and $\mathrm{E}$ values differed significantly from each other $(p<.05)$.

On being interviewed, 19 of the 20 subjects said they were not aware of multiple presentations during the learning phase. The one subject who was aware of it attributed this to the dots and not the figures. This result suggests that attention was indeed withdrawn from the figures during the learning phase. By and large, subjects felt that they were guessing in the test. Three of the 20 subjects were aware that some figures were rotated between the learning and test phase and said they responded by saying "yes" to those figures. These responses in the interview were approximately the same for all the conditions of the experiment, so we do not report them for the other conditions.

Discussion. The maintenance of retinal orientation led to higher recognition than did the maintenance of environmental orientation. Because more $\mathrm{R}$ figures were recognized, these figures must have been encoded or described according to retinal coordinates during the learning phase. Furthermore, because the $E$ figures also must have been described in accordance with the retinal coordinates, they yielded lower recognition as a result of the change in retinal orientation from learning to test.

These results contrast with an earlier finding (Rock \& Heimer, 1957) in which novel figures were presented to upright observers during the learning phase. Later, in the test phase, among other (new) novel figures, the training figures were shown in two orientations. For an observer tilted in the test, one orientation was constant on the retina and the other was constant in the environment. The observer was to say whether or not a particular figure appeared familiar. Attention in this case was not withdrawn from the figures. This resulted in high recognition of environmentally upright figures and a low recognition of retinally upright figures.

\section{Condition 2: Attention Withdrawn, Head Upright}

Condition 2 was identical to Condition 1 with the exception that the subject sat upright during the learning phase. Thus, E test figures were both retinally and environmentally upright and $\mathbf{R}$ test figures were both retinally and environmentally rotated. (Note: $R$ stands for rotated figures for this condition.) Since the $\mathbf{R}$ figures were rotated relative to the retinal and the gravitational coordinate systems, their orientation and form underwent a change with respect to both coordinate systems. Thus, neither coordinate system would be useful in recognition of $\mathbf{R}$ figures. The $\mathbf{E}$ figures, on the other hand, can have conceivably enjoyed the advantage of being upright in two coordinate systems as compared with one. The mean number and percentage of "yes" responses for $N, R$, and $E$ test-figure types are given in Table 1. A one-way, repeated measures ANOVA yielded an $F(2,38)$ of $44.54, p<.01$. An HSD test was used to test the significance of differences between pairs of test-figure types (see Table 3). All three types of test figures differed significantly from one another $(p<.01)$.

Discussion. The results of Condition 2 indicate what is to be expected when subjects are not attending to figures and are shown some figures that remain upright and some that are tilted $90^{\circ}$ in a subsequent test. Recognition parallels the results of many earlier investigations in which subjects were attending to figures. There was a sharp decline in recognizing figures that had changed their orientation by $90^{\circ}$ in Condition 2. Against these results, taken as a baseline, the results of Condition 1 are diametrically different. Figures that remained upright in the environment were recognized less often, and figures that changed their orientation in the environment

Table 1

Mean Number and Percentage of "Yes" Responses in Experiment 1

\begin{tabular}{|c|c|c|c|c|}
\hline $\begin{array}{c}\text { State of attention and orientation } \\
\text { of subject in learning }\end{array}$ & $\begin{array}{c}\text { Figure } \\
\text { type }\end{array}$ & $\begin{array}{l}\text { Mean number } \\
\text { of } \\
\text { "yes" responses }\end{array}$ & $S D$ & $\%$ \\
\hline \multirow{3}{*}{$\begin{array}{l}\text { Condition 1: attention withdrawn, } \\
\text { head tilted }(N=20)\end{array}$} & $\mathrm{E}$ & 3.05 & 1.10 & 50.8 \\
\hline & $\mathbf{R}$ & 4.05 & 1.32 & 67.5 \\
\hline & $\mathbf{N}$ & 1.45 & 0.82 & 22.5 \\
\hline \multirow{3}{*}{$\begin{array}{l}\text { Condition 2: attention withdrawn, } \\
\text { head upright }(N=20)\end{array}$} & E & 3.60 & 1.23 & 60.8 \\
\hline & $* \bar{R}$ & 2.15 & 1.35 & 35.8 \\
\hline & $\mathbf{N}$ & 1.10 & 0.97 & 18.3 \\
\hline \multirow{3}{*}{$\begin{array}{l}\text { Condition 3: attention allocated, } \\
\text { head tilted }(N=16)\end{array}$} & E & 3.88 & 0.96 & 64.6 \\
\hline & $\mathbf{R}$ & 2.31 & 1.19 & 38.5 \\
\hline & $\mathrm{N}$ & .5 & 0.63 & 8.3 \\
\hline \multirow{3}{*}{$\begin{array}{l}\text { Condition 4: attention allocated, } \\
\text { head upright }(N=16)\end{array}$} & $\mathrm{E}$ & 4.0 & 1.09 & 66.7 \\
\hline & ${ }^{*} \mathrm{R}$ & 2.62 & 1.45 & 43.8 \\
\hline & $\mathbf{N}$ & .56 & 0.81 & 9.4 \\
\hline
\end{tabular}

Note. $\mathrm{E}=$ environmentally unchanged, ${ }^{*} \mathrm{R}=$ rotated, $\mathrm{R}=$ retinally unchanged, $\mathrm{N}=$ new.

${ }^{a}$ All subjects were upright for all figures in the recognition test.

${ }^{b}$ Each subject saw six figures in a given orientation in each condition so that the maximum number correct was 6 . 
Table 2

Differences Between Means of Test-Figure Types in Condition 1

\begin{tabular}{clll}
\hline & \multicolumn{3}{c}{ Test-figure type } \\
\cline { 2 - 4 } Test-figure type & $\mathrm{N}$ & $\mathrm{R}$ & $\mathrm{E}$ \\
\hline $\mathbf{N}$ & - & $2.60^{* *}$ & $1.60^{* *}$ \\
$\mathbf{R}$ & - & - & $1.0^{*}$ \\
$\mathrm{E}$ & - & - & - \\
\hline
\end{tabular}

Note. $\mathrm{N}=$ new, $\mathrm{R}=$ retinally unchanged, $\mathrm{E}=$ environmentally unchanged. Critical honestly significant difference $=1.10, p<.01$; $0.86, p<.05$.

$* p<.05 .^{* *} p<.01$.

were recognized more often. Thus, it would appear that what mattered for recognition in Condition 1 was the maintenance of retinal orientation. The $\mathbf{R}$ figures remained in the same orientation with respect to the retina, and the $E$ figures were changed with respect to that orientation.

\section{Condition 3: Attention Allocated, Head Tilted}

To briefly review the procedure, in the learning phase the subjects were instructed to ignore the dots and to look at the figure when it appeared. The test phase was identical to the those of Conditions 1 and 2.

The purpose of Condition 3 was to provide an attention control for Condition 1 . The mean number and percentage of "yes" responses for $\mathrm{N}, \mathrm{R}$, and $\mathrm{E}$ test-figure types are reported in Table 1 . The main finding was essentially a replication of the previously observed superiority of environmentally based recognition when figures are attended to (Rock, 1956, 1973; Rock \& Heimer, 1957). A one-way, repeated measures ANOVA yielded an $F(2,30)$ of $62.10, p<$ .01 . An HSD test was used to test the significance of differences between pairs of test-figure types (see Table 4). All three types of test figures differed significantly from one another ( $p$ $<.01$ ).

Discussion. The results of Condition 3 were exactly opposite to those of Condition 1 in that the environmentally upright figures were better recognized than the retinally upright ones (see Figure 3). Maintenance of retinal orientation did not provide an advantage for recognition under conditions of attention because correction led to an environmentally based description during learning. Thus, the memory based on a description of $\mathbf{R}$ figures did not find a match during the

Table 3

Differences Between Means of Test-Figure Types in Condition 2

\begin{tabular}{cccc}
\hline & \multicolumn{3}{c}{ Test-figure type } \\
\cline { 2 - 4 } Test-figure type & $\mathbf{N}$ & $\mathbf{R}$ & $\mathrm{E}$ \\
\hline N & - & 1.05 & 2.50 \\
$\mathrm{R}$ & - & - & 1.45 \\
E & - & - & - \\
\hline
\end{tabular}

Note. $\mathrm{N}=$ new, $\mathrm{R}=$ rotated, $\mathrm{E}=$ environmentally unchanged. Critical honestly significant difference $=.69, p<.01$. All differences are significant at $p<.01$. test phase. The E figures, on the other hand, were described in accordance with the environmental coordinates and were thus recognized to a higher degree.

\section{Condition 4: Attention Allocated, Head Upright}

Condition 4 was identical to Condition 3 with the exception that the subjects sat upright during the learning phase. This served as a control for both attention and head tilt. Thus, the $R$ figures of the test set were rotated with respect to both retinal and environmental coordinates. (Note: $R$ stands for rotated figures in this condition). On the other hand, E figures maintained their orientation with respect to both the retinal and environmental coordinates. The mean number and percentage of "yes" responses for N, R, and E test-figure types are reported in Table 1. A one-way, repeated measures ANOVA yielded an $F(2,30)$ of $42.01, p<.01$. An HSD test for differences between pairs of means for test-figure types was used (see Table 5). All three test-figure types differed significantly from one another $(p<.01)$.

Discussion. Environmentally unchanged figures in Condition 4 were described in accordance with environmental coordinates during learning, and they were recognized in the test because this description found a match in memory. On the other hand, $\mathbf{R}$ figures were less recognizable because their rotation led to an altered description that did not find a match in memory.

\section{Discussion of Experiment 1}

The main question investigated in Experiment 1 was the effect of inattention on form description. The lack of attention led to a significant increase in descriptions consistent with projective orientation relative to the retinal coordinates. In both of the two head-tilted conditions (Conditions 1 and 3), the mean number correct for the $\mathrm{E}$ and $\mathrm{R}$ test-figure types differed significantly from one another, but the differences were in opposite directions. That is, the distributions for $\mathbf{R}$ and $E$ figures were reversed, showing a predominance of responses based on retinal orientation in Condition 1 (attention withdrawn) and on environmental orientation in Condition 3 (attention allocated). The only difference between these two conditions was the allocation of attention.

It is interesting to note the similarity between the pattern of results for Conditions 3 (head tilted) and 4 (head upright), which were both attention-allocated conditions. Recognition of $\mathrm{R}$ or retinally upright figures in Condition 3 was not different from or superior to recognition of the $\mathbf{R}$ or retinally rotated figures in Condition 4 under conditions of attention. Similarly, recognition of E figures in Conditions 3 and 4 was about equal. Thus, it can be concluded that uprightness of the image on the retina did not facilitate recognition and tilt of the image on the retina did not interfere with recognition under conditions of attention, a finding that has been obtained previously (Rock, 1973).

It is also interesting to note the similarity between the pattern of results for the two head-upright conditions (Conditions 2 and 4). Thus, whether subjects were attending or 
Table 4

Differences Between Means of Test-Figure Types in Condition 3

\begin{tabular}{cccc}
\hline & \multicolumn{3}{c}{ Test-figure type } \\
\cline { 2 - 4 } Test-figure type & $\mathrm{N}$ & $\mathrm{R}$ & $\mathrm{E}$ \\
\hline $\mathrm{N}$ & - & 1.81 & 3.38 \\
$\mathrm{R}$ & - & - & 1.57 \\
$\mathrm{E}$ & - & - & - \\
\hline
\end{tabular}

Note. $\mathbf{N}=$ new, $\mathbf{R}=$ retinally unchanged, $\mathrm{E}=$ environmentally unchanged. Critical honestly significant difference $=.95, p<.01$. All differences are significant at $p<.01$.

not, figures that remained in the same orientation in the environmen $i$ tended to be recognized and those that changed that orientation in the environment tended not to be recognized.

There were a few features of Experiment 1 that were not completely ideal. One was the nature of the numerosity distraction task. Another was the fact that the new figures introduced in the recognition test were not used in learning in a counterbalanced design. Thus, the argument can be made that they were not of equal difficulty to the other figures that were seen in learning and test. A third was the fact that only a tilt of $90^{\circ}$ was investigated. Experiment 2 was designed to deal with these limitations and also to determine if the main

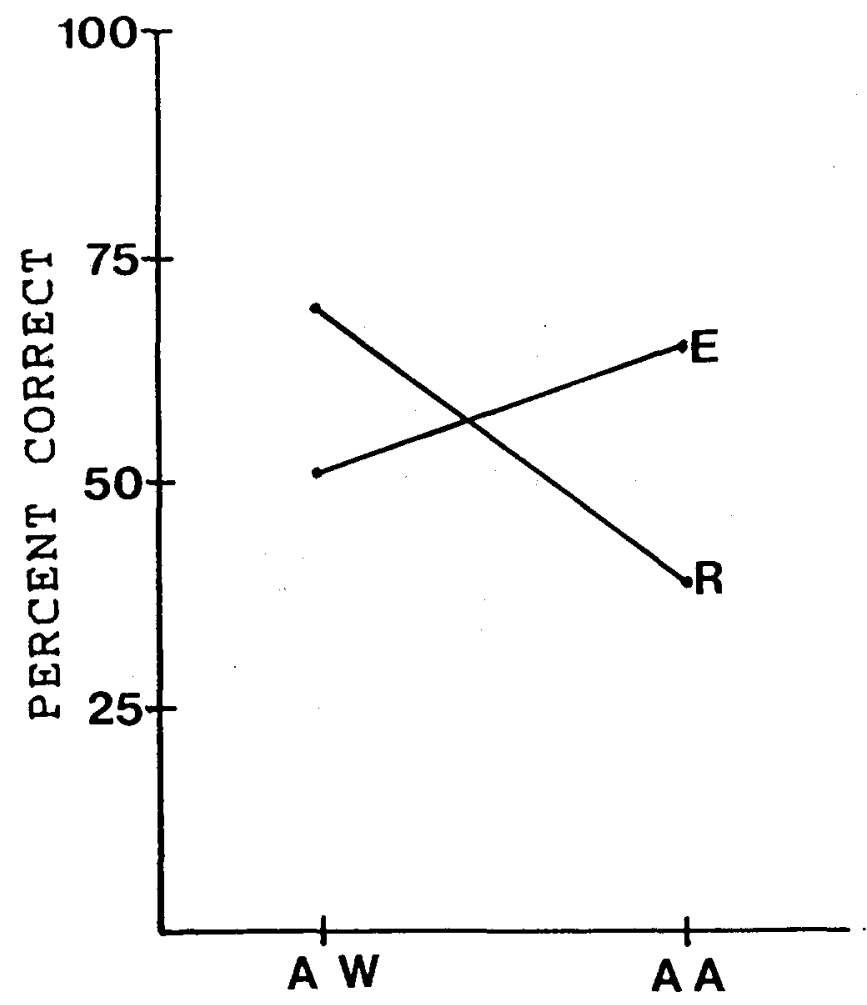

Figure 3. Results of Conditions 1 and 3 of Experiment 1 showing the reversal in percentage of recognition of retinally unchanged $(R)$ and environmentally unchanged (E) test-figure types as a function of attention ( $\mathrm{AW}=$ attention withdrawn; $\mathrm{AA}=$ attention allocated). findings on retinally based description under conditions of inattention could be replicated.

\section{Experiment 2}

Experiment 2 consisted of two conditions of attention: divided and full. Under such attention conditions subjects assumed three head orientations: upright, tilted $90^{\circ}$, and tilted $180^{\circ}$.

\section{Method}

\section{Subjects}

Thirty-six unpaid undergraduates at Rutgers University participated in this experiment. Eighteen students were subjects in the attention-divided condition and 18 in the full-attention condition for partial fulfillment of a course requirement.

\section{Apparatus}

The apparatus used in Experiment 2 was the same as that in Experiment 1, with the following additions. An inclined plane structure was constructed on which subjects could lie supine and view the stimuli with head upside down. The plane was inclined with its lower end next to the tachistoscope. The tachistoscopic fields were circular rather than square. This latter change was not necessary (see comment in Apparatus of Experiment 1) but a circular field is obviously one that can introduce no bias for coordinate directions in any orientation.

\section{Figures}

The figures were prepared in the same way as in Experiment 1. There were three learning phases and three test phases in this experiment. The set of figures used during the learning phases shall be described first.

Learning set. Each card consisted of a central figure (visual angle approximately $2.25^{\circ}$ ) and a peripheral distractor array. For this experiment a new distractor task was used that we considered to be an improvement over the one previously used in that attention was now distracted uniformly in all directions and thus was directionally neutral.

Two of the figures used in Experiment 1 were retained for Experiment 2, and 22 additional figures were prepared. The criteria for selection were that the figures should undergo a change in phenomenal appearance due to tilts of both $90^{\circ}$ and $180^{\circ}$. For example, figures symmetrical about a vertical axis would not be likely to undergo phenomenal change as a result of a $180^{\circ}$ tilt because they would then remain symmetrical about a vertical axis. Hence, such figures would not be included in the experiment.

The distractor array consisted of five outline figures (each subtending a visual angle of $.33^{\circ}$ ) located at the apices of an imaginary regular pentagon (see Figure 4). These figures were either all circles or four circles and one square. Between these small figures and the central figure was a circle that separated the two. The position of the small square among the small circles was varied randomly from one test card to the next. As is apparent from Figure 3, the small figures did not contribute to selective processing in any given direction, unlike the dot clusters used in Experiment 1 that might have created an oblique frame of reference. It is possible, however, that for cards on which a square was present instead of all circles, attention was 
Table 5

Differences Between Means of Test-Figure Types in Condition 4

\begin{tabular}{cccc}
\hline & \multicolumn{3}{c}{ Test-figure type } \\
\cline { 2 - 4 } Test-figure type & $\mathrm{N}$ & $\mathrm{R}$ & $\mathrm{E}$ \\
\hline $\mathrm{N}$ & - & 2.06 & 3.44 \\
$\mathrm{R}$ & - & - & 1.38 \\
$\mathrm{E}$ & - & - & - \\
\hline
\end{tabular}

Note. $\mathrm{N}=$ new, $\mathrm{R}=$ rotated, $\mathrm{E}=$ environmentally unchanged. Critical honestly significant difference $=1.19, p<.01$. All differences are significant at $p<.01$.

selectively diverted. This potentially unwanted selective processing was offset by presenting each figure twice, once with all circles and once with four circles and one square in the periphery.

Test set. Test-set cards contained only the central figure and the surrounding circle. The distractor array was not included.

\section{Procedure}

The experiment consisted of three learning phases and three test phases. Each subject went through a learning phase in three different orientations, namely, $0^{\circ}, 90^{\circ}$, and $180^{\circ}$. Immediately following each learning phase the subject sat upright and was given a recognition test. Before beginning the first learning phase the subject was made familiar with the task and two practice trials were given. During the practice session the subject always sat upright. The subjects were divided into two groups: an attention-divided group and a fullattention group. The subjects in the attention-divided group were instructed to perform two tasks. They were asked to discriminate between the two kinds of distractor arrays by saying "same" to the all-circles array or "different" to the array comprising four circles and one square. They were also told to memorize the central figures and

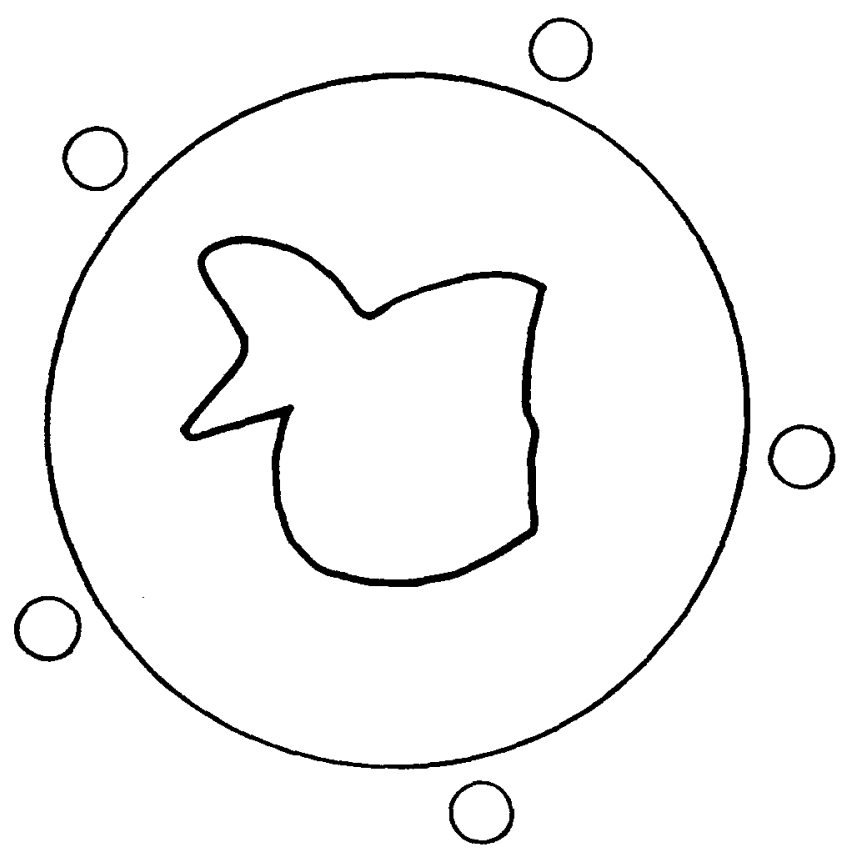

Figure 4. One of the figures used in Experiment 2 with the samedifferent task consisting of circles in the periphery. that their memory would later be tested. The subjects in the fullattention group were instructed to ignore the distractor array and to memorize the central figures.

Learning phase. After the practice session the subject was asked to assume the first of the three head orientations. The order of these orientations was randomized across subjects. The head-upright orientation required the subjects to sit upright with their chin resting on a chin rest. The head $-90^{\circ}$ orientation required the subjects to tilt their head and rest it on the horizontal padded surface. For the head- $180^{\circ}$ orientation, the subject lay supine on an inclined surface and bent his or her head backwards until it was inverted, which thus allowed the retinal coordinates to be altered $180^{\circ}$ with respect to gravitational coordinates.

In each orientation and in both conditions the subject was presented with six cards. Each card was presented twice, once with an all-circles distractor array and once with the four circles-one square array. The order of cards was randomized. The presentation time was $300 \mathrm{~ms}$. As in Experiment 1, subjects were required to look at a fixation point ( $2 \mathrm{~mm}$ in diameter) located where the central figure would appear.

Test phase. Immediately following the learning phase for each orientation of the subject, the subject was shown the central figures used in the practice session. The subject always sat upright during the test phase. The subject was asked to say "yes" to this figure and other figures that would be shown if they were from the learning set and otherwise to say "no." The subjects were told to guess if they were uncertain. During each test phase subjects were presented with eight cards, each of which was presented once for $300 \mathrm{~ms}$.

The figures used during the test phase varied depending on the orientation of the subject during the preceding learning phase. When the subject was upright during learning, the test set consisted of figures that were not rotated at all $\left(0^{\circ}\right)$, rotated $90^{\circ}$, rotated $180^{\circ}$, or new. Thus two figures were upright, four figures were rotated (two $90^{\circ}$ and two $180^{\circ}$ ), and two figures were new. For subjects who were tilted $90^{\circ}$ during learning, the test set consisted of three upright figures, three $90^{\circ}$ figures, and two new figures. For subjects who were tilted $180^{\circ}$ during learning, the figures used during the test phase were three upright, three rotated $180^{\circ}$, and two new ones. Thus, for subjects who were tilted in learning, aside from the new figures, the test figures remained either retinally upright $(R)$ or environmentally upright $(E)$. As in Experiment 1, figures seen in the test phase by subjects who were tilted $90^{\circ}$ degrees clockwise in the learning phase were tilted $90^{\circ}$ counterclockwise. Thus these figures remained in the same orientation on the retina. When the subject was upright in learning, the test figures either remained both retinally and environmentally unchanged or were tilted with respect to both the retina and the environment. Unlike Experiment 1, the new figures were used equally often as learning-set figures. In other words, the use of R, E, and N figures in the test was counterbalanced.

\section{Results}

The mean number and percentage of "yes" responses are given in Table 6 for both groups. Considering the full-attention condition first, it can be seen that the results correspond to those of Experiment 1. When the subject was always upright there was a decline in recognition from a mean of $1.67(83 \%)$ to a mean of .72 (33\%) for figures that were tilted $90^{\circ}$ in the test, and a decline to a mean of $.94(47 \%)$ when the figures were inverted in the test. (The maximum possible number of yes responses was 2.) For the subject-upright condition a oneway, repeated measures ANOVA yielded an $F(3,51)$ of $17.8, p$ $<.01$. An HSD test was carried out to compare pairs of means 
Table 6

Mean Number and Percentage of "Yes" Responses in Experiment 2

\begin{tabular}{|c|c|c|c|c|c|c|c|c|}
\hline \multirow[b]{2}{*}{$\begin{array}{c}\text { Orientation of subjects } \\
\text { in learning }\end{array}$} & \multicolumn{4}{|c|}{ Full attention $(N=18)$} & \multicolumn{4}{|c|}{ Divided attention $(N=18)$} \\
\hline & $\begin{array}{c}\text { Orientation of figures } \\
\text { in test }\end{array}$ & $M^{\mathrm{b}}$ & $S D$ & $\%$ & $\begin{array}{l}\text { Orientation of } \\
\text { figures } \\
\text { in test }\end{array}$ & $M^{\mathrm{b}}$ & $S D$ & $\%$ \\
\hline \multirow[t]{4}{*}{ Upright } & $\mathrm{E} 0^{\circ}$ & 1.67 & .48 & 83 & $\mathrm{E} 0^{\circ}$ & 1.72 & .46 & 86 \\
\hline & ${ }^{*} \mathrm{R} 90^{\circ}$ & 0.72 & .57 & 36 & ${ }^{*} \mathrm{R} 90^{\circ}$ & 0.83 & .62 & 42 \\
\hline & ${ }^{*} \mathrm{R} 180^{\circ}$ & 0.94 & .72 & 47 & ${ }^{*} \mathrm{R} 180^{\circ}$ & 0.89 & .90 & 44 \\
\hline & $\mathbf{N}$ & 0.22 & .43 & 11 & $\mathrm{~N}$ & 0.39 & .50 & 19 \\
\hline \multirow[t]{3}{*}{ Tilted $90^{\circ}$} & $\mathrm{E} 0^{\circ}$ & 2.22 & .65 & 74 & $\mathrm{E} 0^{\circ}$ & 1.39 & .60 & 46 \\
\hline & R $90^{\circ}$ & 1.17 & .92 & 39 & R $90^{\circ}$ & 1.89 & .90 & 63 \\
\hline & $\mathrm{N}$ & 0.33 & .48 & 17 & $\mathrm{~N}$ & 0.33 & .48 & 17 \\
\hline \multirow[t]{3}{*}{ Upside down $\left(180^{\circ}\right)$} & $\mathrm{E} 0^{\circ}$ & 1.94 & .72 & 65 & $\mathrm{E} 0^{\circ}$ & 1.39 & .78 & 46 \\
\hline & $\mathrm{R} 180^{\circ}$ & 2.00 & .84 & 67 & R $180^{\circ}$ & 1.94 & .80 & 65 \\
\hline & $\mathrm{N}$ & 0.22 & .43 & 11 & $\mathrm{~N}$ & 0.33 & .48 & 17 \\
\hline
\end{tabular}

Note. $\mathrm{E}=$ environmentally unchanged; ${ }^{*} \mathrm{R}=$ rotated, but unlike in head-tilt conditions, not retinally upright; $\mathrm{R}=$ retinally unchanged; $\mathrm{N}=$ new.

${ }^{a}$ All subjects were upright for all figures in the recognition test.

${ }^{b}$ The total number of figures seen by each subject in a given orientation in each condition was as follows: two for each of the four test-figure types when the subject was upright in learning; two for the $\mathrm{N}$ test figures when the subject was tilted $90^{\circ}$ or $180^{\circ}$ in learning; and three for the $E$ and $R$ test figures when the subject was tilted $90^{\circ}$ or $180^{\circ}$ in learning. Thus the maximum number correct was either two or three.

between test-figure types (see Table 7). As would be expected, upright test figures $(E)$ were significantly better recognized than either $90^{\circ}$ - or $180^{\circ}$-tilted figures. The higher recognition for the inverted figures $(47 \%$ ) was not significantly better than recognition of the $90^{\circ}$ tilted figures (36\%), but the trend was in the direction of previous findings (Rock, 1973).

When the subject was tilted $90^{\circ}$ in learning, recognition declined from a mean of 2.22 (74\%) for E figures to a mean of 1.17 (39\%) for $\mathrm{R}$ figures. (The maximum possible number of yes responses was 3 , see Table 6.) A repeated measures ANOVA yielded an $F(1,17)$ of $18.0, p<.01$. This pattern of results was quite similar to those in which the subject remained upright, again corresponding to the results of Experiment 1 and previous results (Rock, 1973). As can be seen in Table 6, there was little gain for R $(39 \%$ vs. $36 \%)$ and little loss for $E$ test figures ( $74 \%$ vs. $83 \%)$, compared with the results when the subject remained upright. When the subject was tilted $180^{\circ}$ recognition was equal for the $E$ and $R$ test figures. Moreover, the results do suggest a decline in recognition for $\mathrm{E}$ test figures compared with when the subject was upright $(65 \%$ vs. $83 \%)$ and an increase in recognition for $R$ test figures compared with when the subject was upright $(67 \%$ vs. $47 \%)$.

Table 7

Differences Between Means of Test-Figure Types: FullAttention Subject Upright in Learning

\begin{tabular}{ccccc}
\hline & \multicolumn{4}{c}{ Test-figure type } \\
\cline { 2 - 5 } Test-figure type & $\mathrm{N}$ & $\mathrm{R} 90^{\circ}$ & $\mathrm{R} 180^{\circ}$ & $\mathrm{E}$ \\
\hline $\mathrm{N}$ & - & .50 & $.72^{*}$ & $1.45^{*}$ \\
$\mathrm{R} 90^{\circ}$ & - & - & .22 & $.95^{*}$ \\
$\mathrm{R} 180^{\circ}$ & - & - & - & $.73^{*}$ \\
$\mathrm{E}$ & - & - & - & - \\
\hline
\end{tabular}

Note. $\mathrm{N}=$ new, $\mathrm{R}=$ rotated, $\mathrm{E}=$ environmentally unchanged. Critical honestly significant difference $=.66, p<.01 ; .53, p<.05$. $* p<.01$.
For the attention-divided group only the results for the subject-upright condition corresponded to those of the fullattention group, in that recognition of upright figures was good (mean number of yes responses was $1.72-86 \%$ ) and recognition of tilted and inverted figures was poor (means of 0.83 [42\%] and 0.89 [44\%], respectively). A one-way, repeated measures ANOVA yielded an $F(3,51)$ of $12.11, p<.01$. An HSD test was carried out to compare the means for different pairs of test-figure types (see Table 8). As might be expected, upright $(E)$ figures were recognized significantly better than either $90^{\circ}$ - or $180^{\circ}$-tilted figures. When the subject was tilted $90^{\circ}$ the results were essentially a replication of the finding in Experiment 1 that when allocation of attention to a novel figure was restricted, the resulting description was more consistent with that figure's retinal orientation than with its environment orientation. The independent measures ANOVA yielded a significant difference between the full-attention and attention-divided groups for $90^{\circ}$ head-tilted subjects, $F(1,34)$ $=5.65, p<.05$, with respect to $\mathrm{R}$ "yes" responses. The attention-divided subjects recognized a larger number of retinally upright figures than did the full-attention subjects. For the subject-inverted condition, subjects did better with inverted or $\mathbf{R}$ than upright or $\mathrm{E}$ test figures (means of 1.94 [65\%] and 1.39 [46\%], respectively), although the difference was of borderline significance, $F(1,17)=3.43, p=.087$.

\section{Discussion of Experiment 2}

The results of Experiment 2, insofar as the $0^{\circ}$ and $90^{\circ}$ conditions are concerned, correspond quite closely with the results of Experiment 1. In both cases, the effect of lessened attention to the figures resulted in better recognition for tilted figures that remained retinally unchanged than for figures that remained environmentally unchanged.

However, there was no comparable condition in Experiment 1 for the $180^{\circ}$ orientation condition of Experiment 2. The fact is that, even under conditions of attention, figures 
Table 8

Differences Between Means of Test-Figure Types: DividedAttention Subject Upright in Learning

\begin{tabular}{ccccc}
\hline & \multicolumn{4}{c}{ Test-figure type } \\
\cline { 2 - 5 } Test-figure type & $\mathrm{N}$ & $\mathrm{R} 90^{\circ}$ & $\mathrm{R} 180^{\circ}$ & $\mathrm{E}$ \\
\hline N & - & .44 & .50 & $1.33^{*}$ \\
$\mathrm{R} 90^{\circ}$ & - & - & .06 & $.89^{*}$ \\
$\mathrm{R} 180^{\circ}$ & - & - & - & $.83^{*}$ \\
$\mathrm{E}$ & - & - & - & - \\
\hline
\end{tabular}

Note. $\mathrm{N}=$ new, $\mathrm{R}=$ rotated, $\mathrm{E}=$ environmentally unchanged. Critical honestly significant difference $=.74, p<.01 ; .60, p<.05$.

$* p<.01$.

that remained upright (E) were not recognized as well when subjects viewed them from an inverted position of the head (65\% correct) as when the subjects were upright throughout ( $83 \%$ correct); figures that were inverted $(R)$ were recognized quite well when the subjects viewed them from an inverted head position (67\% correct) in comparison with recognition of inverted figures when subjects were upright throughout (47\% correct). Thus, regression to retinal orientation was evidenced even under conditions of attention. For that reason, the attention-divided condition only revealed a small additional decline in recognition of upright (E) figures $(46 \%$ correct) and no additional improvement in recognition of inverted ( $R$ ) figures (65\% correct) in comparison with the full-attention condition when subjects were inverted in learning.

\section{General Discussion}

Considering first the results of conditions in which subjects were paying attention, we see that they were consistent across the two experiments and with earlier findings as well. Table 9 presents the results of recognition under conditions of attention in Experiment 1, Experiment 2, and an experiment conducted by Rock and Heimer (1957). The data in the first row reflect the change in appearance of figures when they were not in the same orientation with respect to the environment in the learning and test sets. In these conditions the subject was upright throughout. There was always a decline in recognition, but the absolute magnitude of recognition varied from experiment to experiment, as might be expected. It is worth noting again that in Experiment 2 the trend for complete inversion of a figure was in the direction of somewhat better recognition (47\%) than that for a $90^{\circ}$ tilt (33\%).

The important point revealed in Table 9, by comparison of the second row with the first row, is the fact that when the subject was tilted $90^{\circ}$ in learning there was little change in recognition. That is to say, despite the change in retinal orientation, figures that remained upright in the environment were recognized about as well as when the subject remained upright; figures that were tilted, so as to remain in the same retinal orientation, were not recognized any better. Thus, under these conditions there was no loss from retinal change and no gain from retinal identity, a finding also seen in the earlier experiment by Rock and Heimer (1957).

The effect of inversion of the subject's head, however, was somewhat different. If we compare the first- and third-row (Experiment 2) recognition scores in Table 9, we see that there was a drop in recognition of upright figures and a gain in recognition of inverted figures. So, for $180^{\circ}$ change, there was a loss from retinal change and a gain from retinal identity. The same kind of effect was obtained in earlier research (Rock, 1956, 1973). We have already pointed out that this fact itself is evidence for the reality of a level of figural description based on the retinal-egocentric coordinates. Because the correction for retinal inversion is difficult to achieve under these conditions, there is a regression to the retinally determined description.

We can now compare the results of attending to the figures with those of inattention or divided attention. For this purpose Table 10 is organized in the same way as Table 9 , but there is no earlier comparable experiment of inattention or divided attention to include here. The top row shows the effect on recognition of changing the orientation of a figure in the environment when viewed throughout by upright subjects. Interestingly enough, the pattern of results was similar to that obtained when subjects were attending to the figures. There was a sharp drop in recognition from upright to $90^{\circ}$-tilted figure but no further decline for inverted figures. Once again we see that inversion did not produce less recognition than a tilt of $90^{\circ}$.

However, when the subjects were tilted $90^{\circ}$, the pattern of results was the very opposite of that obtained under conditions of attention. Compare the second row in Table 10 with the top and second rows of Table 9. Figures that remained upright in the environment were recognized less often than when viewed by an upright subject. The decline in Experiment 2

Table 9

Percentage of Recognition of Upright and Disoriented Figures Under Conditions of Attention

\begin{tabular}{|c|c|c|c|c|c|c|c|}
\hline \multirow{3}{*}{$\begin{array}{l}\text { Orientation } \\
\text { of subjects } \\
\text { in learning }\end{array}$} & \multicolumn{2}{|c|}{ Experiment 1} & \multicolumn{3}{|c|}{ Experiment 2} & \multicolumn{2}{|c|}{ Rock and Heimer (1957) } \\
\hline & \multirow{2}{*}{$\begin{array}{c}\text { Test } \\
\text { figure upright }\end{array}$} & \multirow{2}{*}{$\begin{array}{c}\text { Test } \\
\text { figure disoriented } \\
90^{\circ}\end{array}$} & \multirow{2}{*}{$\begin{array}{c}\text { Test } \\
\text { figure upright }\end{array}$} & \multicolumn{2}{|c|}{$\begin{array}{c}\text { Test } \\
\text { figure } \\
\text { disoriented }\end{array}$} & \multirow{2}{*}{$\begin{array}{c}\text { Test } \\
\text { figure upright }\end{array}$} & \multirow{2}{*}{$\begin{array}{c}\text { Test } \\
\text { figure disoriented } \\
90^{\circ}\end{array}$} \\
\hline & & & & $90^{\circ}$ & $180^{\circ}$ & & \\
\hline Subject upright & 67 & 44 & 83 & 33 & 47 & 72 & 32 \\
\hline Subject tilted $90^{\circ}$ & 65 & 39 & 74 & 39 & & 69 & 42 \\
\hline Subject upside down & - & - & 65 & & 67 & - & - \\
\hline
\end{tabular}

Note. Subjects were either upright for both learning and test (first row) or tilted in learning and upright in test (second and third rows). In the Rock and Heimer (1957) experiment, subjects were upright in learning and tilted in the test. 
Table 10

Percentage of Recognition of Upright and Disoriented Figures Under Conditions of Inattention or Divided Attention

\begin{tabular}{|c|c|c|c|c|c|}
\hline \multirow{3}{*}{$\begin{array}{l}\text { Orientation } \\
\text { of subjects } \\
\text { in learning }\end{array}$} & \multicolumn{2}{|c|}{ Experiment 1} & \multicolumn{3}{|c|}{ Experiment 2} \\
\hline & \multirow{2}{*}{$\begin{array}{l}\text { Figure } \\
\text { upright }\end{array}$} & \multirow{2}{*}{$\begin{array}{c}\text { Figure } \\
\text { disoriented } \\
90^{\circ}\end{array}$} & \multirow{2}{*}{$\begin{array}{l}\text { Figure } \\
\text { upright }\end{array}$} & \multicolumn{2}{|c|}{$\begin{array}{c}\text { Figure } \\
\text { disoriented }\end{array}$} \\
\hline & & & & $90^{\circ}$ & $180^{\circ}$ \\
\hline Subject upright & 61 & 36 & 86 & 42 & 44 \\
\hline Subject tilted $90^{\circ}$ & 51 & 68 & 46 & 63 & - \\
\hline Subject upside down & - & - & 46 & - & 65 \\
\hline
\end{tabular}

Note. Subjects were either upright for both learning and test (first row) or tilted in learning and upright in the test (second and third rows).

was particularly large. Figures that were tilted $90^{\circ}$, so that they were retinally and egocentrically upright, showed an increase in recognition. The increase was particularly striking in Experiment 1 . See also the graphs in Figures 3 and 5. This pattern of results was different from any earlier findings on the effect of observer disorientation on figure recognition. The effect of inversion of the subject's head was to lower recognition of upright figures and to raise recognition of inverted figures, an effect obtained under conditions of attention, but it was greater under conditions of divided attention.

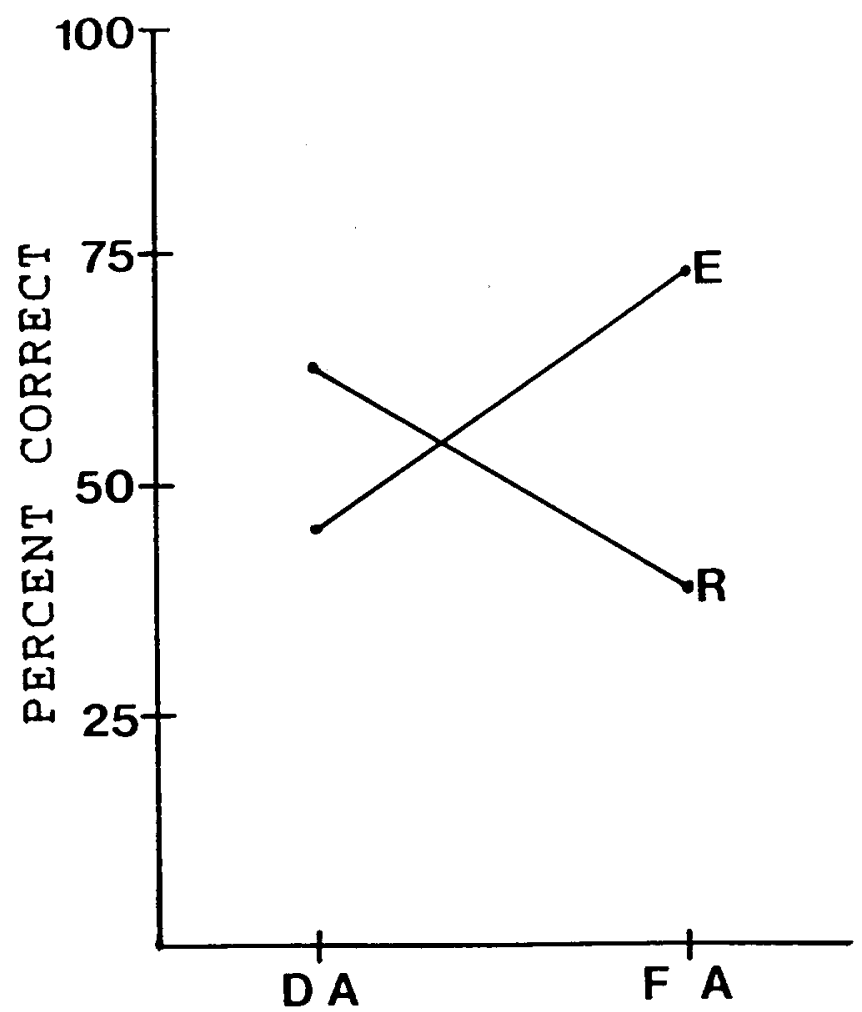

Figure 5. Results of Experiment 2 for the $90^{\circ}$ head-tilted conditions showing the reversal in percentage of recognition of retinally unchanged $(R)$ and environmentally unchanged $(E)$ test-figure types as a function of attention ( $D A=$ divided attention; $F A=$ full attention).
We interpret these findings as support for the existence of a stage in processing of a description of an object based on its orientation in relation to the observer. In both experiments, it was during the learning stage that inattention to or diverted attention from the central figure was brought about. Consequently, it was at that time that the process of correction was arrested by virtue of insufficient attention. The subject achieved a perception based on the interplay of the geometry of the figure and the assignment of directions to it based on the more primitive retinal-egocentric coordinates. Hence, that description was the one encoded in memory and the one available for recognition at the time of the test.

The results point in the direction one would predict on the basis of this interpretation but are not entirely in accord with it. In each experiment one particular result deviated somewhat from it. In Experiment 1, when the subjects in the inattention condition were tilted $90^{\circ}$ in learning, were they to achieve only a retinally based percept, they would be expected to do as well with a tilted figure in the test when they were upright (because the figure was then unchanged retinally) as subjects did with upright figures when they were upright throughout. They did so, recognition being $68 \%$ and $61 \%$, respectively. When these subjects, tilted in learning, viewed an upright figure in the test, they would be expected to do as poorly as did subjects upright throughout who viewed a tilted figure in the test. The reason for this is they presumably would not encode it in terms of its environmental coordinates. However, they did better, recognition being $51 \%$ and $36 \%$, respectively. This finding suggests that either attention was not completely withdrawn from the figure in the learning stage or, if it were, some processing beyond the retinally based description occurred.

In Experiment 2 the opposite was the case for the inattention condition. Subjects tilted $90^{\circ}$ in learning did as poorly with figures upright in the test $(46 \%)$ as subjects who remained upright throughout did with figures tilted in the test (42\%). But those subjects tilted in learning also did more poorly with figures disoriented in the test $(63 \%)$ than did subjects who remained upright throughout with upright test figures $(86 \%)$. The latter finding suggests that the retinally based encoding per se was not as good or as durable as encoding when an upright subject saw an upright figure. Another way of looking at this result is to say that when a subject who was upright in both learning and test viewed a figure that was upright in the test, the maintenance of the figure's orientation was with respect to both environmental and egocentric coordinates, whereas when a subject who was tilted in learning viewed a figure that was tilted in the test the maintenance of orientation was only with respect to egocentric coordinates. Description on the basis of both coordinate systems may have resulted in a more enduring representation than description on the basis of only one coordinate system; at least this may have been true under conditions of lessened attention.

One might ask why it is that subjects in the inattention conditions of Experiment 1 perceived and acquired memories of the figures presented in the learning session. The instructions were such that the subjects had no reason at all to devote any attention to the figures in the center of the cards. Previous research has demonstrated that there is no significant recog- 
nition of figures that have been viewed under conditions of inattention (Butler \& McKelvie, 1985; Rock \& Gutman, 1981; Rock, Schauer, \& Halper, 1976). (This problem did not arise in Experiment 2 because subjects were told to divide their attention). We cannot fully resolve this question, but the fact is that in Experiment 1 each figure was seen three times for $500 \mathrm{~ms}$. The conditions differ from those of the previous research. We arrived at them by intuition and trial and error rather than on the basis of theory. However, one might speculate that, given the repetitions of the figures, subjects, having become somewhat proficient at the "same" or "different" task concerning the dots, could afford to divert some attention to the perception of the central figure. Against this speculation is the fact that in the interview afterward subjects seemed to be unaware of the repetitions and, in the recognition test, claimed that they were guessing. Yet they clearly did recognize the figures if one goes by performance rather than phenomenal experience. In fact, their performance was roughly equivalent to that of the subjects in the attention conditions, as can be seen by comparing the entries in Table 4 with those in Table 3 for Experiment 1 . The only difference is that there were more false-positive responses in the inattention conditions than in the attention conditions.

Because the focus of the present research was on the effect that withdrawal of attention might have on form perception rather than on attention per se, we did not pursue further the interesting question of why form perception did occur in Experiment 1. In other words, the manipulation of attention was for us a method or tool to allow investigation of its effects on level of processing, so that we were content to find a procedure in which, despite diverted attention, we were able to achieve the learning necessary to conduct the experiment.

Can the conditions of inattention in these experiments have the effects they had for reasons having little, if anything, to do with inattention per se and the regression to egocentric from environmental coordinates, as we were predicting? An affirmative answer to this question would put these experiments in an extremely different light. For example, suppose what the subjects did, given the instructions about attending to the numerosity of same-different task pertaining to the peripheral stimuli, was to move their eyes differently than when they attended to the central figure, or to process peripheral rather than central regions of the central figures, or to process details rather than the whole configuration. As to eye movement, the use of a fixation mark and the limited duration of exposure would severely limit it. For example, in Experiment 2 the exposure period was only $300 \mathrm{~ms}$, and it is generally agreed that no eye movement can be executed within $200 \mathrm{~ms}$, so if any eye movement did occur it could not have been more than one saccade. We believe that the data rule out such alternative explanations. If it were factors of this kind that mattered, then one would expect a similar decline in recognition when the subject was upright. Yet in both Experiments 1 and 2, the level of recognition under conditions of lessened attention when the subject was upright during the learning phase was not significantly different from that in fullattention conditions: In Experiment 1 the level of recognition for figures upright was $61 \%$ versus $67 \%$ and for figures tilted was $36 \%$ versus $44 \%$, respectively, for conditions of inatten- tion and attention. In Experiment 2 the level of recognition for figures upright was $86 \%$ versus $83 \%$, for figures tilted $90^{\circ}$ was $42 \%$ versus $36 \%$, and for figures tilted $180^{\circ}$ was $44 \%$ versus $47 \%$, respectively, for conditions of inattention and attention. Thus, it seems entirely justified to conclude that lessened attention resulted in the effect we were predicting, namely, processing the figures on the basis of egocentric rather than environmental coordinates. This difference in processing would not be evident when the subject remained upright because the egocentric and environmental coordinates were aligned.

The requirements of the experiment imposed certain restrictions on the selection of the figures to be used. First, it was obviously important that the figures had to be such that they would often fail to be recognized when their orientation was changed in the test. Otherwise we could hardly investigate whether inattention resulted in failure to recognize figures whose orientation in the environment remained unchanged, because of a change in their egocentric orientation. Now not all figures become unrecognizable as a result of altered orientation. Certainly familiar ones such as alphanumeric characters do not. Nor do figures with a strong intrinsic axis of their own (Rock, 1973; Wiser, 1981). Nor is it likely that figures with distinctive local features, or parts or landmarks, would become unrecognizable, because such parts are likely to make the figure "orientation free."

These considerations would seem to require the use of figures that are novel or unfamiliar and that have a holistic shape without distinctive parts that are likely to be recognizable regardless of orientation. A great many kinds of figures can be generated that would meet these criteria, for example, whether curvilinear or rectilinear, open or closed, simple or complex. The kind of figure we used is illustrated in Figures 2 and 4 . The figures are stylistically similar to those that have been used successfully in the past to study the effect of change of orientation on form (Rock, 1973). A shape meeting these criteria is perceived on the basis of how its orientation is woven into a structural description that includes its geometry. However, it is important to point out that the generality of any results obtained with the figures we used to other kinds of figures is not the main point of this research. We are seeking not to make general claims about all types of figures, but to test a theoretical issue, specifically, a hypothesis about the role of attention in the process of correcting for retinal disorientation. What is required are figures that will allow for a test of that hypothesis. We believe the kind we selected do allow for such a test.

It can be argued that ordinarily there is no prior stage of description based on retinal orientation that then requires correction. In daily life or in experiments on recognition, when the observer is tilted,

there is little time for correction to occur... [and] it is more likely that the perceptual system is pretuned to a particular subjective reference frame, and that retinal information is incorporated directly into that frame. Such a system would maintain the smooth flux of perception in everyday life despite a regular occurrence of head and body tilts. (Corballis, Anuze, \& Blake, 1978, p. 283) 
At the same time those making this argument can acknowledge that form description on the basis of retinal coordinates does occur under certain conditions, such as in viewing a figure in a horizontal plane or, as was found here, under conditions of inattention. The argument would be that we can impose a retinally based reference frame and do so under certain conditions but do not do so ordinarily, as when we are tilted in viewing an upright scene.

However, there are reasons for believing that description based on retinal orientation does occur even when information is available to a tilted observer from gravity and visual cues as to the directional coordinates in the environment. We mentioned earlier that despite correction, even simple figures such as letters or numbers look different when they are not retinally upright (see Figure 1), and this remains true if we observe such figures when they are upright and we are tilted. We then have a dual awareness of their shape based on the correct assignment of direction and on retinal directional coordinates. It is the presence of the latter description that makes these figures look odd. Therefore the pretuning does not eliminate the retinally determined description.

In experiments performed by Corballis, Nagourney, Shetzer, and Stefanatos (1978), the reaction time of tilted observers was measured for the identification of simple patterns in various orientations. Latency was governed primarily by how the patterns were oriented in the environment rather than how they were oriented in relation to the observer. The plot relating latency to degrees of disorientation with respect to the vertical was essentially the same when the observer's head was upright and when it was tilted $\left(60^{\circ}\right)$. The investigators concluded that these results argue against the primary of a "retinal factor" in the perception of orientation.

There are two points we could make about Corballis, Nagourney, et al.'s (1978) study. The first is that from the plot of the results it seems that, in two of the experiments, reaction time was shorter when upright subjects viewed upright figures than when tilted subjects viewed upright figures. This suggests that a correction process was required for the tilted subjects and it took time. The second point concerns the method. For tilted subjects, the region uppermost in the scene governs the assignment of directions to the patterns presented, and for this reason in virtually all our earlier research and in the attention conditions of the experiments reported here, recognition remained high for environmentally upright figures and low for environmentally tilted figures, even when these tilted figures were egocentrically upright. Therefore, in the experiment by Corballis, Nagourney, et al. (1978), when the tilted subject was shown a figure tilted to the same degree, even though it was first described in terms of its retinal coordinates, in respect to which it was upright, that description would nonetheless be superseded by one based on the environmental coordinates. Consequently, there would be no reduction in latency by virtue of uprightness of the retinal image. We would suggest a modification of the procedure in which the correct orientation of each figure as it is about to be displayed be given by an arrow. In other words, the arrow should point to the real top of the environmentally tilted figure, that is, the region that in fact is not now uppermost in the scene. We believe that latency would then be a direct function of retinal orientation.
Still another reason for believing in the occurrence of a retinally based description, despite the simultaneous presence of information as to an object's orientation in the environment, is one also alluded to earlier. When conditions are such that the achievement of the environmentally based description is difficult, we either fail to recognize objects or regress to an egocentrically based description. But if the perceptual system is pretuned to a particular reference frame, why is recognition so adversely affected by departures from upright retinal orientation under such conditions, and why is recognition then governed primarily by retinal orientation?

What are the theoretical implications of our findings? With respect to the problem of orientation and form, the results support our view that the seemingly unchanged perception and undiminished recognition that typically occurs in viewing objects that are upright in the environment from a tilted position of one's body (Rock, 1973) do indeed require a process of correction. That process occurs in two stages, the first of which is a description based on an interplay of the figure's geometry and its egocentric orientation and the second of which is a description based on the interplay of the figure's geometry and its environmental orientation. The withdrawal of attention from such processing arrests the process at the first stage and thus leads to what we are calling a regression to an egocentrically based description.

Regarding our borrowing of the term regression from Thouless (1947), it should be noted that he meant to say that the percept regresses from the real object (what would be complete veridicality) to a compromise in the direction of a perept that would be based simply on the proximal stimulus. Constancy is usually not fully achieved either in daily life or in experiment. What we mean by regression is that without attention the correction process fails to occur so that the percept is more or less totally based on retinal orientation. It is not a matter of compromise.

The broader theoretical implication of our research is that once again the evidence supports the view that inattention can arrest processing at an earlier stage. Thus, shape or size constancy can be said to require an earlier stage of processing in which shape or size based on the retinal image is first extracted (Epstein \& Broota, 1986; Epstein \& Lovitts, 1985). Only with attention can the processing continue to the stage at which information concerning surface slant or distance can be brought to bear on the proximal stimulus, thus resulting in shape or size perception that takes account of such information. If this reasoning is correct, then our findings and those of others such as Epstein and his co-workers support a theory of perception, or at least of perceptual constancy, that is more in line with the notion of unconscious inference (von Helmholtz, 1867/1962), perceptual coupling (Epstein, 1982; Hochberg, 1974), or an algorithmic processing approach (Ebenholtz, 1977; Epstein, 1977) than with the notion of the extraction of invariant stimulus information (Gibson, 1950, 1966).

However, an alternative explanation of the Epstein \& Broota (1986) and Epstein \& Lovitts (1985) experiments, as the authors acknowledge, is that constancy fails under conditions of inattention, not because information about slant or distance is not taken into account by the perceptual system, but because that information is not extracted. Thus, if the 
slanted ellipse appears to be in the frontoparallel plane or the distant square appears to lie in the plane of the viewing aperture, then neither shape nor size constancy could be expected to occur. Our finding is less subject to this kind of interpretation. It seems unlikely that a tilted subject would no longer perceive veridically which orientation in the environment is vertical simply because of inattention. Thus our interpretation that perception of form regresses to egocentric orientation when attention is distracted is, to repeat, that the description of a form is then based on its egocentric coordinate direction rather than that there is any misperception of its environmental coordinate direction.

Our findings supporting the reality of retinally based egocentric coordinates bear on the problem first investigated by George Stratton $(1896,1897)$ on adaption to a reinverted retinal image. Although the results of Stratton's famous experiment remain controversial, there is a less well-known theoretical question that the experiment raised that also remains unresolved. The question is this: With respect to what can the entire visible scene that Stratton viewed through his lens system be said to be inverted? Stratton himself came to the conclusion that one cannot speak of the uprightness or invertedness of an entire modality in any absolute sense and that it was with respect to preestablished connections between vision and touch that the optically inverted scene can be said to be upside down. Consistent with this belief, he claimed that the adaptation he did achieve was based on the reestablishment of harmony between these modalities. Some years later Harris (1965) made a similar argument, buttressing it with data that revealed visual capture whenever vision and tactual (or proprioceptive) perceptions were thrown into conflict and the ultimate adaptive shift in such nonvisual perception.

Although it is undoubtedly true that some of Stratton's adaptations concerned the reinterpretation of proprioceptive information by virtue of visual dominance, we do not believe that the way to understand the Stratton experiment is in terms of initially created sensory disharmony with the eventual shift toward harmony. We suggest instead that the question, "With respect to what can the entire optically inverted scene be said to be inverted?" can be answered, "with respect to the biologically primitive egocentric coordinates that are rooted in the retinal coordinates." In other words, the phenomenal inversion one experiences on first looking through an inverting optical device is directly visual; it is not merely intersensory. Therefore, although the lens scene displays appropriate relations such as that the visible head is nearest the visible sky, the visible feet on the visible ground, as Bishop Berkeley $(1709 / 1910)$ noted with respect to the normally inverted retinal image, the fact is that the sky in the lens scene looks "down" and the ground looks "up" at the outset and, in our opinion, continues to do so throughout the experiment. That genuine visual adaptation did not occur in Stratton's experiment-witness the absence of a negative after-effect on removing the lenses-or, in our opinion, in subsequent repetitions of it for even longer durations (Ewert, 1930; Köhler, 1964: Kottenhoff, 1957: Snyder \& Pronko, 1952), supports the view that the retinally based egocentric coordinate system is indeed primitive and innate. Were the problem simply one of intersensory disharmony, given what we now know about the plasticity of the haptic-proprioceptive system and the dominance of vision, one ought to expect rapid and enduring adaptation to optical inversion.

The issue under investigation here is not directly related to the phenomenon of mental rotation (Shepard \& Metzler, 1971). The kind of phenomenon studied here concerns the effect of orientation on spontaneous form perception. In mental rotation, which one might regard not so much a perceptual process as an imagined one, the phenomenon is one of the effect of deliberate intention to rotate an object to some other orientation. However, it is true that a process similar to mental rotation may occur in the correction of an object, the image of which is not upright on the retina (see Rock, 1973). It is likely that the limitations of this kind of process explain why correction for figural rotations of $180^{\circ}$ (or of observer rotations of $180^{\circ}$ when viewing an upright object) and correction for figures such as inverted faces are so difficult to achieve. It is not yet entirely clear whether "correction" as defined here is simply one application of mental rotation. There are obvious similarities but also certain differences, and we are now investigating this very question.

\section{References}

Berkeley, G. (1910). An essay towards a new theory of vision. New York: E. P. Dalton. (Original work published 1709).

Butler, L., \& McKelvie, S. J. (1985). Processing of form: Further evidence for the necessity of attention. Perceptual and Motor Skills, 61, 215-221.

Corballis, M. C., Anuza, T., \& Blake L. (1978). Tachistoscopic perception under head tilt. Perception \& Psychophysics, 24, 274284.

Corballis, M. C., Nagourney, B. A., Shetzer, L. I., \& Stefanatos, G. (1978). Mental rotation under head tilt: Factors influencing the location of the subjective reference frame. Perception \& Psychophysics, 24, 263-273.

Ebenholtz, S. (1977). The constancies in object orientation: an algorithm processing approach. In w. Epstein (Ed.), Stability and constancy in visual perception: Mechanisms and processes. (pp. 7189) New York: Wiley-Interscience.

Epstein, W. (1977). Historical introduction to the constancies. In W. Epstein (Ed.), Stability and constancy in visual perception: Mechanics and processes (pp. 1-22) New York: Wiley-Interscience.

Epstein, W. (1982). Percept-percept couplings. Perception, 11, 75-83.

Epstein, W., \& Broota, K. D. (1986). Automatic and attentional components in perception of size-at-a-distance. Perception \& Psychophysics, 40, 256-262.

Epstein, W., \& Lovitts, B. E. (1985). Automatic and attentional components in perception of shape-at-a-slant. Journal of Experimental Psychology: Human Perception and Performance, 11, 355366.

Ewert, P. H. (1930). A study of the effect of retinal stimulation upon spatially coordinated behavior. Genetic Psychology Monographs, 1 (3\&4).

Gibson, J. J. (1950). The perception of the visual world. Boston: Houghton Mifflin.

Gibson, J. J. (1966). The senses considered as perceptual systems. Boston: Houghton Mifflin.

Harris, C. S. (1965). Perceptual adaptation to inverted, reversed and displaced vision. Psychological Review, 72, 419-444.

Hochberg, J. (1974). Higher-order stimuli and inter-response couplings in the perception of the visual world. In R. B. MacLeod \& 
H. L. Pick (Eds.), Perception: Essays in honor of J. J. Gibson Ithaca, NY: Cornell University Press.

Köhler, I. (1964). The formation and transformation of the perceptual world. Psychological Issues, 3, 1-173.

Köhler, W. (1940). Dynamics in psychology. New York: Liveright.

Kottenhoff, H. (1957). Situational and personal influences on space and perception with experimental spectacles: Part 1. Prolonged experiment with inverting glasses. Acta Psychologica, 13, 79-97.

Rock, I. (1954) The perception of the egocentric orientation of a line. Journal of Experimental Psychology, 48, 367-374.

Rock, I. (1956). The orientation of forms on the retina and in the environment. American Journal of Psychology, 69, 513-528.

Rock, I. (1973). Orientation and form. New York: Academic Press.

Rock, I., \& Gutman, D. (1981). The effect of inattention of form perception. Journal of Experimental Psychology, 7, 275-285.

Rock, I., \& Heimer, W. (1957). The effect of retinal and phenomenal orientation on the perception of form. American Journal of Psychology, 70, 493-511.

Rock, I., Schauer, R., \& Halper, F. (1976). Form perception without attention. Quarterly Journal of Experimental Psychology, 28, 429440.

Shepard, R. N., \& Metzler, J. (1971). Mental rotation of threedimensional objects. Science, 171, 701-703.
Snyder, F. W., \& Pronko, N. H. (1952). Vision with spatial inversion. Wichita, KS: University of Wichita Press.

Stratton, G. M. (1896). Some preliminary experiments on vision without inversion of the retinal image. Psychological Review, 3, 611-617.

Stratton, G. M. (1897). Vison without inversion of the retinal image. Psychological Review, 4, 341-360, 463-481.

Thouless, R. (1947). The experience of "upright" and "upside down" in looking at pictures. In l'Institut Supérieur of Philosophie, Louvain (Ed.), Miscellanea Psychologia, Albert Michotte (p. 130). Paris: Libraire Philosophique, Joseph Vrin.

von Helmholtz, H. (1962). Treatise on physiological optics (Vol. 3, J. P. C. Southall, Ed. and Trans.). New York: Dover. (Original work published in German, 1867, and in English, 1925).

Wiser, M. (1981). The role of intrinsic axes in shape recognition. In Proceedings, Third Annual Conference of the Cognitive Science Society. (pp. 184-186). Berkeley, California.

Received January 18, 1988. Revision received May 11, 1988

Accepted June 27, 1988 